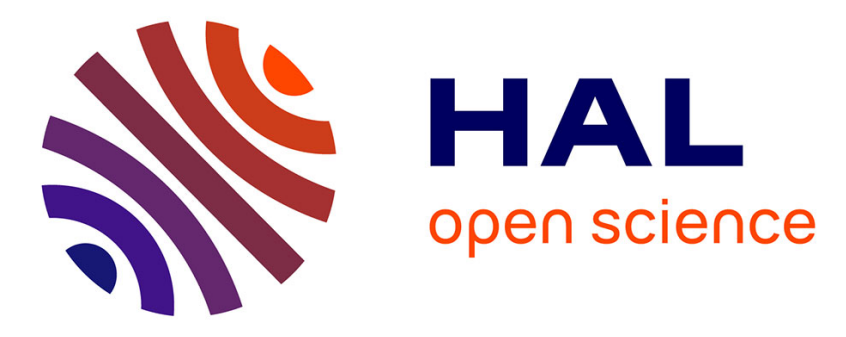

\title{
On the influence of ionizing radiation on the electrical properties of short-channel MOS transistors
}

Gérard Sarrabayrouse, M. Gamboa, J. Buxo, P. Rossel, J.M. Charlot, M. Roumeguere

\section{- To cite this version:}

Gérard Sarrabayrouse, M. Gamboa, J. Buxo, P. Rossel, J.M. Charlot, et al.. On the influence of ionizing radiation on the electrical properties of short-channel MOS transistors. Revue de Physique Appliquée, 1980, 15 (5), pp.941-944. 10.1051/rphysap:01980001505094100 . jpa-00244810

\section{HAL Id: jpa-00244810 https://hal.science/jpa-00244810}

Submitted on 1 Jan 1980

HAL is a multi-disciplinary open access archive for the deposit and dissemination of scientific research documents, whether they are published or not. The documents may come from teaching and research institutions in France or abroad, or from public or private research centers.
L'archive ouverte pluridisciplinaire HAL, est destinée au dépôt et à la diffusion de documents scientifiques de niveau recherche, publiés ou non, émanant des établissements d'enseignement et de recherche français ou étrangers, des laboratoires publics ou privés. 


\title{
On the influence of ionizing radiation on the electrical properties of short-channel MOS transistors
}

\author{
G. Sarrabayrouse, M. Gamboa, J. Buxo and P. Rossel \\ Laboratoire d'Automatique et d'Analyse des Systèmes \\ 7, avenue du Colonel-Roche, 31400 Toulouse, France
}

J. M. Charlot, M. Roumeguere

Commissariat à l'Energie Atomique, Centre d'Etude de Bruyères le Châtel 92120 Montrouge, France

(Reçu le 13 décembre 1979, révisé le 29 janvier 1980, accepté le 29 janvier 1980)

\begin{abstract}
Résumé. - L'influence d'un rayonnement ionisant sur la conductance de sortie d'un transistor MOS à canal court est examinée. Les dégradations subies sont dues å la création de nouveaux états de surface à l'interface $\mathrm{SiO}_{2}-\mathrm{Si}$ et non à une éventuelle modification de la vitesse limite des porteurs.
\end{abstract}

\begin{abstract}
The effect of ionizing radiation on the output conductance of a short-channel MOS transistor is examined. It appears that these effects are predominantly caused by the increase of the surface state density and that no noticeable effect due to the change of the carriers' saturation velocity has been detected.
\end{abstract}

1. Introduction. - The degradation of the electrical properties of MOS transistors under ionizing radiation has been generally related to the creation of both, a radiation induced surface-state density at the $\mathrm{Si}$ $\mathrm{SiO}_{2}$ interface and a density of fixed positive charges within the gate field oxide [1]. These two physical effects make the mobility and the threshold voltage $V_{\mathbf{T}}$ of the transistor evolve under irradiation.

In the case of a short-channel MOS transistor, a supplementary degradation effect has been detected. Indeed, the customary negative conductance values appear to change into positive ones after irradiation in particular for large values of the drain current. Once the experimental results have been shown, the paper discusses the physical origin of the former phenomenon. Two possibilities are compared in detail; either a change in the carrier' saturation velocity [2] or the influence of the radiation-induced surface state density.

2. Preliminary considerations. - P. Rossel et $a l$. [3] have shown recently that the output dc conductance of a short-channel MOS transistor can be expressed by :

$$
G \equiv R_{\mathrm{e}}[Y(\omega)]_{\omega=0}=G_{\mathrm{D}}-k \cdot R_{\mathrm{th}} I_{\mathrm{D}}\left(I_{\mathrm{D}}-I_{\mathrm{c}}\right)
$$

where $Y(\omega)$ is the transistor admittance when it is submitted to a signal of angular frequency $\omega ; G_{\mathrm{D}}$ is the high frequency conductance, $R_{\text {th }}$ the thermal resistance and $I_{\mathrm{D}}$ the drain current. The symbol $I_{\mathrm{c}}$ stands for the drain current value that makes the admittance imaginary part $\operatorname{Im}[Y(\omega)]$ vanish and $k$ is a coefficient such that :

$$
\operatorname{Im}[Y(\omega)]_{\max }=-\operatorname{Im}\left[Z_{\mathrm{th}}(\omega)\right]_{\max } k \cdot I_{\mathrm{D}}\left(I_{\mathrm{D}}-I_{\mathrm{c}}\right)
$$

where $Z_{\mathrm{th}}(\omega)$ is the transistor's thermal impedance. Relationships (1) and (2) show that in order to study the output conductance $G$ as a function of the radiation dose it is necessary to study experimentally the two quantities : $G_{\mathrm{D}}$ and $\operatorname{Im}[Y(\omega)]_{\max }$.

3. Experimental results. - The studied devices are V-MOS transistors of channel length $L=1.2 \mu \mathrm{m}$ and gate oxide capacitance per unit channel length $Z C_{\mathrm{ox}}=8.4 \times 10^{-8} \mathrm{~F} \mathrm{~cm}^{-1}$. The surface orientation of the channel is $\langle 111\rangle$. The transistors have been irradiated with X-rays up to a dose of $10 \mathrm{krad}$.

The device's complex admittance diagram has been obtained by the method described in [3] and its shape before and after irradiation is represented in figure 1. This figure clearly shows that the irradiation brings 


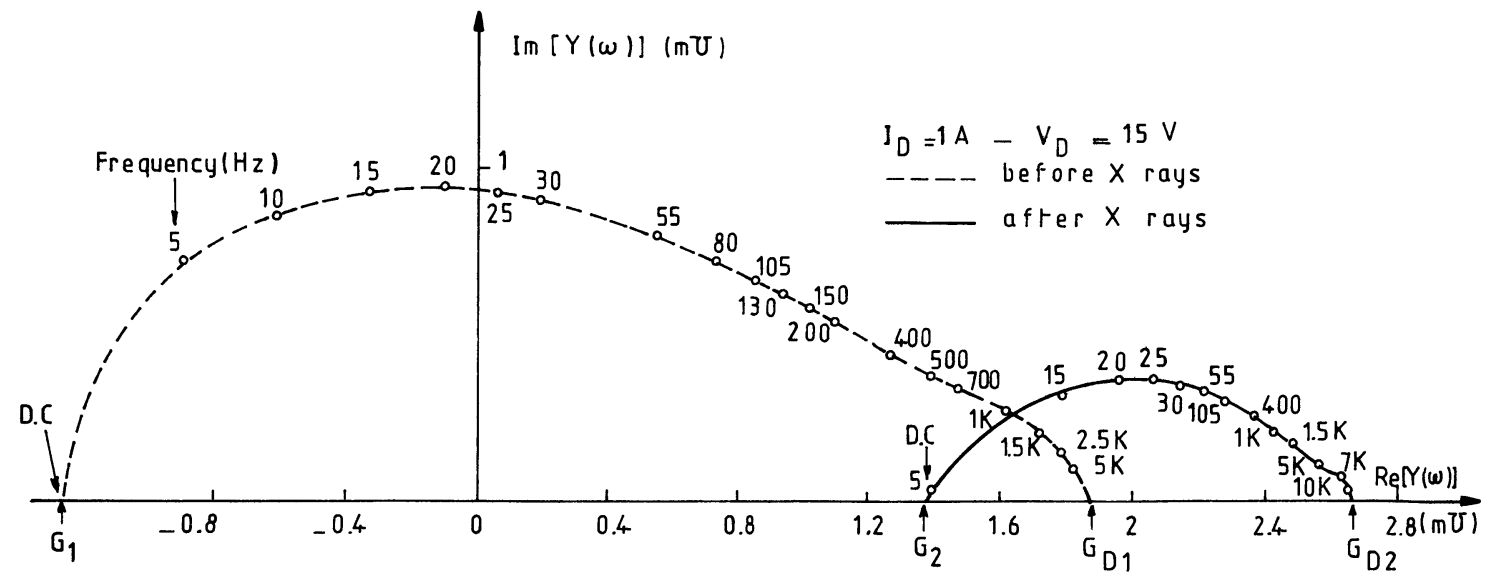

Fig. 1. - Experimental diagram for the complex admittance values before and after irradiation ; the curve parameter is the frequency value.

about a large degradation of the dc conductance value which changes from $G_{1}=-1.26 \mathrm{mU}$ before irradiation to $G_{2}=1.37 \mathrm{mU}$ after irradiation. Moreover the high frequency conductance value changes from

$$
G_{\mathrm{D} 1}=1,88 \mathrm{mU} \text { to } G_{\mathrm{D} 2}=2.67 \mathrm{mU} .
$$

Figure 2 shows the variation of $\operatorname{Im}[Y(\omega)]_{\max }$ as a function of the drain current value $I_{\mathrm{D}}$. These curves show the influence of irradiation on the critical current value $I_{\mathrm{c}}$ which changes from $I_{\mathrm{c} 1}=620 \mathrm{~mA}$ before irradiation to $I_{\mathrm{c} 2}=830 \mathrm{~mA}$ after irradiation.

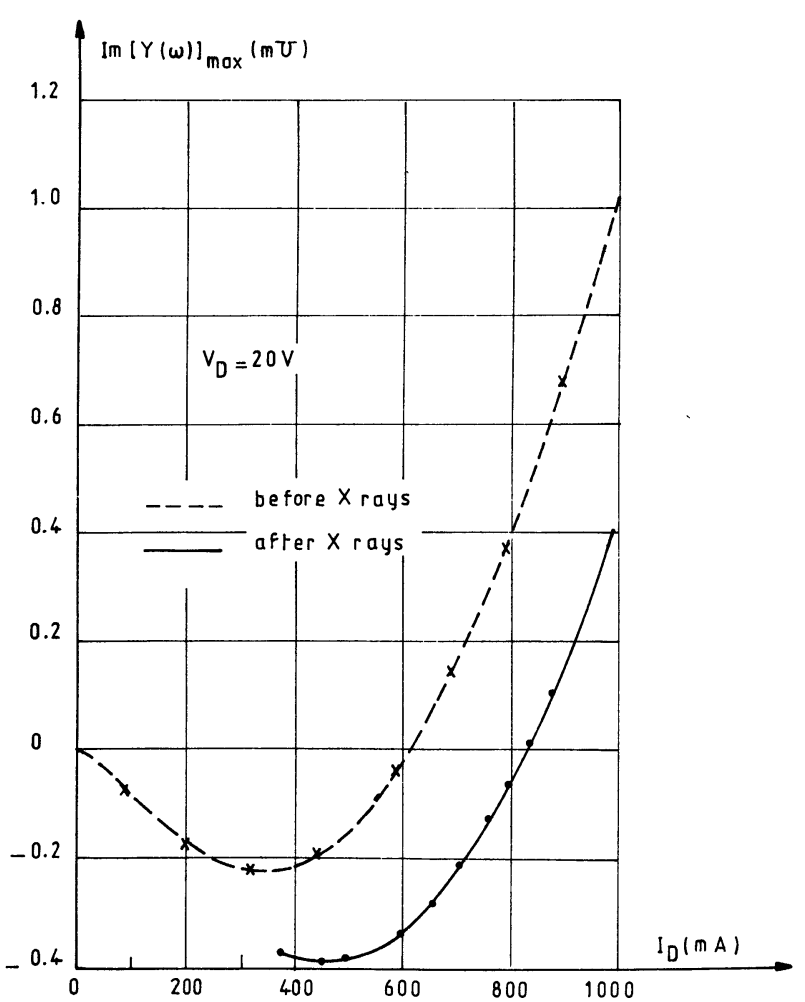

Fig. 2. - Measured values of $\operatorname{Im}[Y(\omega)]_{\max }$ as a function of the drain current.
Figure 3 represents the variation of $\operatorname{Im}[Y(\omega)]_{\max }$ as a function of $I_{\mathrm{D}}\left(I_{\mathrm{D}}-I_{\mathrm{c}}\right)$. It appears that the two straight lines, before and after irradiation are exactly the same which shows that $k$ is a quantity which does not depend upon irradiation. The slope of the curves

$$
\operatorname{Im}[Y(\omega)]_{\max }=f\left[I_{\mathrm{D}}\left(I_{\mathrm{D}}-I_{\mathrm{c}}\right)\right]
$$

is given by $\operatorname{Im}\left[Z_{\mathrm{th}}(\omega)\right]_{\max } \cdot k$. It has been assumed that $\operatorname{Im}\left[Z_{\mathrm{th}}(\omega)\right]_{\max }$ does not depend upon the irradiation dose which is supported by the fact that this quantity is only controled by the bulk semiconductor properties.

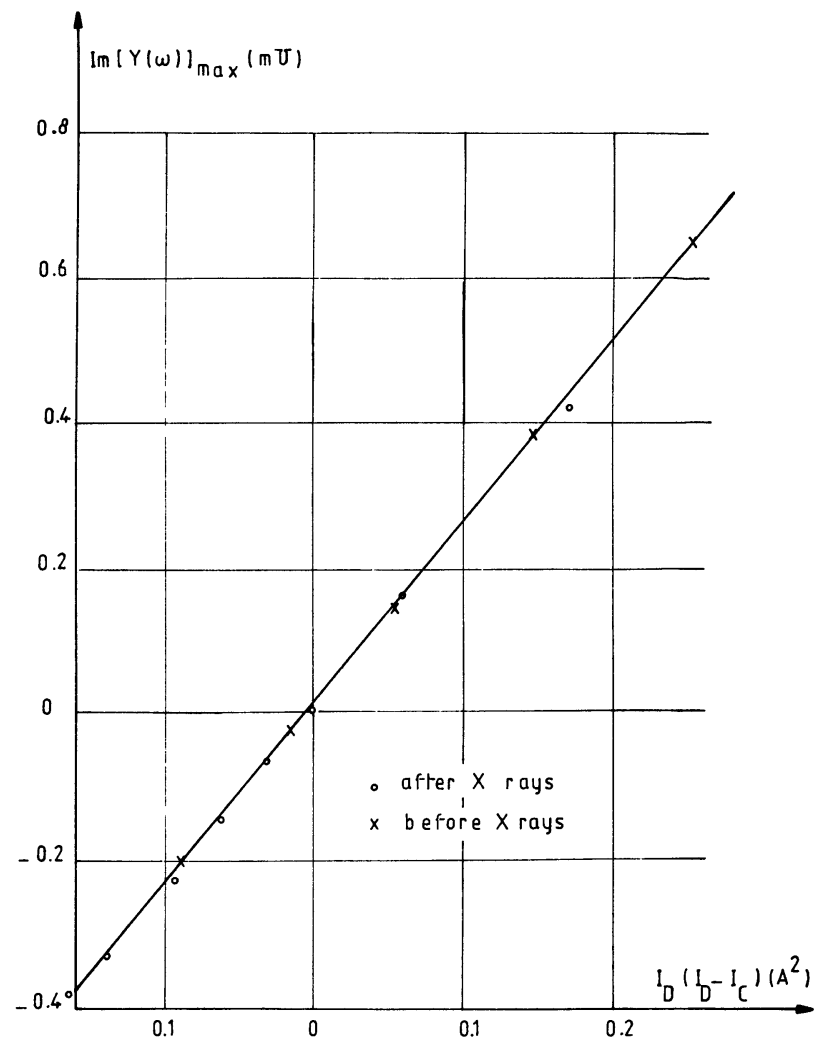

Fig. 3. - Measured values of $\operatorname{Im}[Y(\omega)]_{\max }$ versus $I_{\mathrm{D}}\left(I_{\mathrm{D}}-I_{\mathrm{C}}\right)$. 
4. Discussion of the results. - The preceding results show that the influence of irradiation on the output conductance value $G$ is mainly due to the variation of the critical current value $I_{\mathrm{c}}$. Indeed the slight variation of $G_{\mathrm{D}}\left(G_{\mathrm{D} 2}-G_{\mathrm{D} 1}=0.79 \mathrm{mU}\right)$ cannot account for the much larger variations of the conductance value $\left(G_{2}-G_{1}=2.6 \mathrm{mU}\right)$. In order to specify the physical origin of this influence the meaning of $k$ and $I_{\mathrm{c}}$ will be recalled.

It was recently shown [4] that these two quantities stand for, respectively :

$$
\begin{gathered}
k=-\frac{\partial \ln \left(v_{\text {sat }}\right)}{\partial T} \\
I_{\mathrm{c}}=Z C_{\text {ox }} v_{\text {sat }}^{2}\left(\frac{\partial V_{\mathrm{T}}}{\partial T}\right) \cdot\left(\frac{\partial v_{\text {sat }}}{\partial T}\right)^{-1}
\end{gathered}
$$

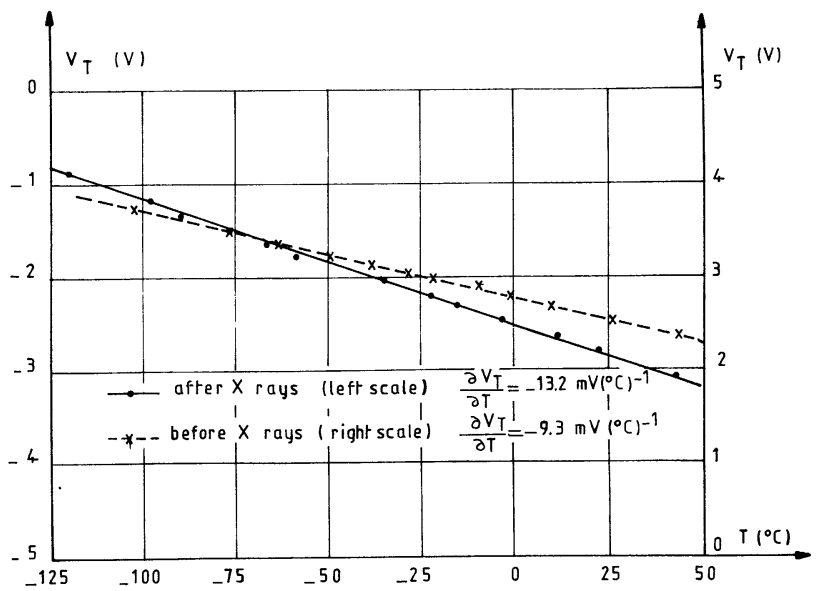

(4) Fig. 4. - Measured value of the threshold voltage $V_{\mathrm{T}}$ versus temperature before and after irradiation.

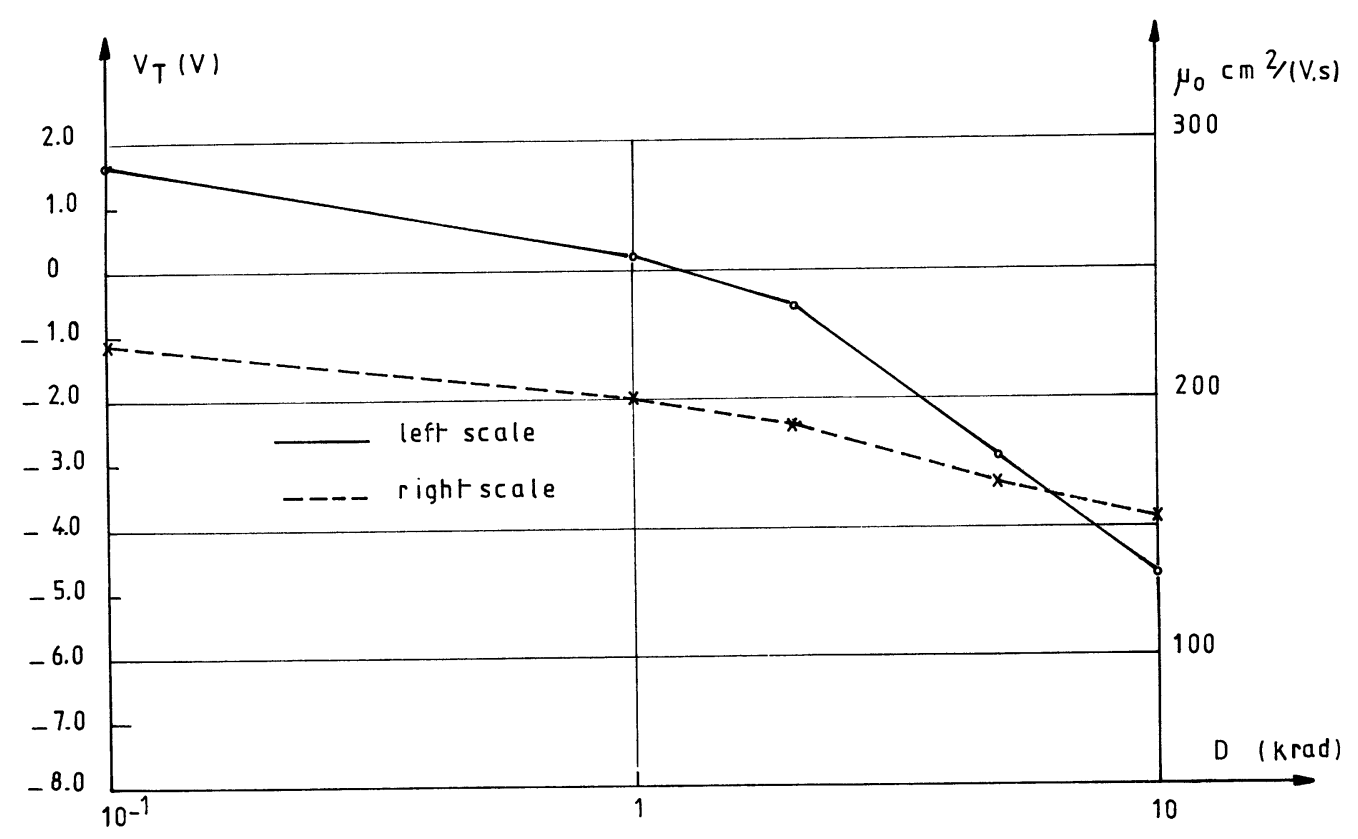

Fig. 5. - Measured values of $V_{\mathrm{T}}$ and of the carriers' mobility $\mu_{0}$ versus the irradiation dose.

where $T$ is the silicon crystal temperature and $v_{\text {sat }}$ the carriers' saturation velocity.

By taking into account the values of both $\left(\partial V_{\mathrm{T}} / \partial T\right)$ (see Fig. 4) and $I_{\mathrm{c}}$ (see text) it appears that under irradiation the variation of $v_{\text {sat }}$ deduced from (3) and (4) :

$$
v_{\text {sat }}=\frac{k}{Z C_{\mathrm{ox}}} I_{\mathrm{c}}\left(\frac{\partial V_{\mathrm{T}}}{\partial T}\right)^{-1}
$$

is less than $6 \%$.

This small value is to be compared with the large variations of the mobility value $(\approx 27 \%)$ represented in figure 5.

This result shows that the $\mathrm{Si}_{-} \mathrm{SiO}_{2}$ interface properties do not affect the carrier saturation velocity. Indeed the large variation of both $V_{\mathrm{T}}$ and $\mu_{0}$ under irradiation shown in figure 5 must be interpreted in terms of a degradation of the $\mathrm{SiO}_{2}-\mathrm{Si}$ interfaces.

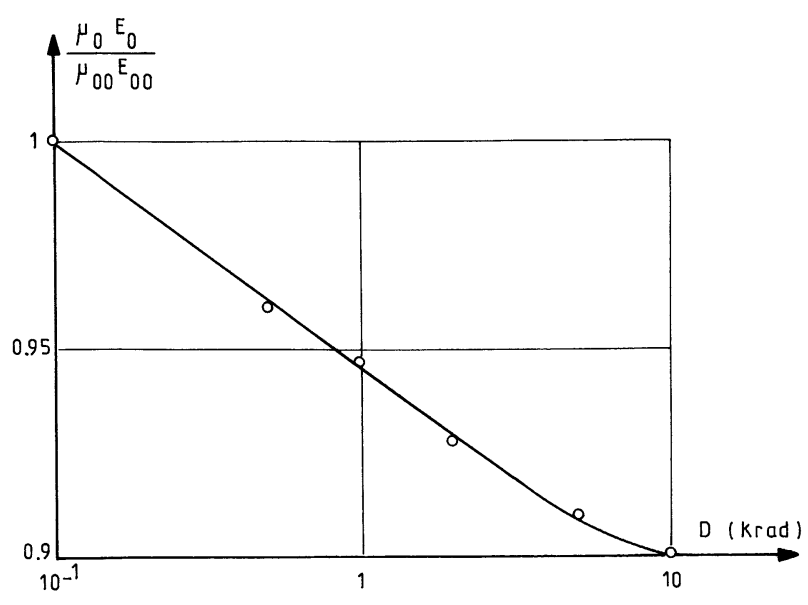

Fig. 6. - Measured variations of $\mu_{0} E_{0}$ versus radiation dose $-\mu_{00}$ and $E_{00}$ stand respectively for the values of $\mu_{0}$ and $E_{0}$ before irradiation. 
However this does not mean the commonly used relation :

$$
v_{\text {sat }} \approx \mu_{0} \cdot E_{0}
$$

where $E_{0}$ is the longitudinal critical electric field, is not valid after irradiation.

Indeed as it can be shown in figure 6 the quantity $\mu_{0} E_{0}$ is practically constant with the radiation dose $\left({ }^{1}\right)$ (the registered variations are about $10 \%$ for $10 \mathrm{krad}$ radiation dose).

In addition the preceding results show that the sensitivity to irradiation of the output conductance values is mainly due to the radiation induced variation

( $\left.{ }^{1}\right) E_{0}$ has been determined from the high drain voltage section of the drain current-gate voltage curve [5]. of $\left(\partial V_{\mathrm{T}} / \partial T\right)$ and thereby only the electrostatic effect of the surface state density on $V_{\mathrm{T}}\left({ }^{2}\right)$ is responsible for this sensitivity.

5. Conclusion. - It has been shown that the radiation-induced variation of the output conductance of a short channel MOS transistor is mainly due to the creation of a radiation-induced surface-state density at the $\mathrm{Si}_{-} \mathrm{SiO}_{2}$ interface. It has also appeared that the saturation velocity value is not sensitive to radiation doses up to $10 \mathrm{krad}$.

${ }^{2}$ ) The variation of $\partial V_{\mathrm{T}} / \partial T$ cannot be attributed to electric charges within the oxide but to the building of electric charges at the $\mathrm{SiO}_{2}$ - $\mathrm{Si}$ interface as a consequence of the creation of new surface states by irradiation.

\section{References}

[1] Hughes, H. L., I.E.E.E. Trans-on Nucl. Sci., NS 16 (1969) 195.

[2] FANG, F. F. and Fowler, A. B., J. Appl. Phys. 41 (1970) 1825.

[3] Rossel, P., Gamboa, M., Tranduc, H. et Martinot, H., Revue Phys. Appl. 14 (1979) 911.
[4] Gamboa, M., Sarrabayrouse, G., Tranduc, H. et Rossel, P., (Submitted for publication).

[5] Rossel, P., Guegan, G., Martinot, H., Zamorano, M., Revue Phys. Appl. 13 (1978) 591. 